\title{
The role of simulation in neurosurgery
}

\author{
Giselle Coelho • Nelci Zanon • Benjamin Warf
}

Received: 11 August 2014 / Accepted: 2 September 2014 / Published online: 24 September 2014

(C) Springer-Verlag Berlin Heidelberg 2014

It is increasingly apparent that the standards for surgical training are shifting from time-based to criterion-based parameters that emphasize obtaining and maintaining competencies [24]. The formation of a surgeon demands significant dedication and effort, in addition to time [54]. Current, wellestablished methods of surgical training are being challenged as the environment becomes increasingly competitive and litigious with greater scrutiny of patient outcomes [14, 17, $40,44,50]$. In order to increase patient safety and improve treatment outcomes, several strategies such as problem-based learning and objective structured clinical examinations have promoted the development of new curricula in surgical education $[13,15,35,51,52]$.

Some of these changes have been driven by events in the 1980 s and 1990s such as medical misconduct and overworked, unsupervised resident staff that contributed to patient morbidity and mortality. This also coincided with a growing medical malpractice crisis. As a result, regulatory bodies began to initiate new standards of work hour restrictions and supervision for residents in training. The New York Health Code of 1989 compiled regulations restricting resident work hours ( $80 \mathrm{~h}$ per week) and one day free a week and placed limits on the number of calls [24, 32]. Concerns arose about the long-established methods of training surgical residents, and solutions were sought to reduce preventable errors and perioperative complications [24, 9].

G. Coelho $(\bowtie) \cdot$ N. Zanon

Pediatric Neurosurgery Center, Beneficência Portuguesa Hospital, Rua Capitão Mor Roque Barreto n 47 - Térreo, Bela Vista, São Paulo 01323-030, Brazil

e-mail: gigicoelho7@hotmail.com

B. Warf

Department of Pediatric Neurosurgery, Boston Children's Hospital/ Harvard Medical School, Boston, MA, USA
The airline industry, with the development of flight simulators and pilot coaching methods, proved to be an excellent precedent for innovation in surgical education. Many surgical educators believe such methods are keys to accelerating the acquisition of fundamental skills and the rate of performance improvement among surgical residents. A Yale University study demonstrated that criterion-based simulator training decreased operating time by $30 \%$ and operative errors by $85 \%[47,48]$.

Neurosurgical trainees in particular face great challenges in learning to plan and perform increasingly complex procedures in which there is little room for error [10]. The educator's task becomes ever more daunting as the number and complexity of neurosurgical procedures continue to increase in parallel with technological developments such as minimally invasive spine surgery and instrumentation, interventional neuroangiography, image-guided navigation, and endoscopic surgery.

The necessity of innovative surgical curriculum development that incorporates safe learning environments and objective skill assessments is thus obvious and needs to be led by trained surgical educators [5].

Adjuvant, non-clinical, surgical training can be grouped into four broad categories:

1. Cadaver training

2. Animal models

3. Training with synthetic physical models

4. Computerized and virtual reality simulators

Practice with each of these models has particular advantages and disadvantages that are still being elucidated in various validation processes. The choice of the most appropriate training model should take into consideration, among other qualities, efficacy, validity, cost-effectiveness, and versatility [60]. The demand for new, non-clinical, paradigms for surgical skills training has led to the development of a variety 
of surgical simulation models and methods that refine technique while objectively assessing performance $[2,20,42,45$, $56,58]$. Simulation may be defined as a pool of techniques used in conjunction to recreate specific aspects of the real world, thus providing experience in a riskless situation. This concept has gained popularity over the last 20 years, and its broad applicability is exemplified in neuroendoscopy training.

Neuroendoscopy has reemerged as an appealing option in the management of intraventricular lesions and the treatment of hydrocephalus in children and adults. The use of cadaveric specimens for developing neuroendoscopy skills is expensive and increasingly difficult logistically. There are problems with the potential toxicity of chemicals used for fixation as well as logistic limitations related to preservation, storage, and viable utilization time for the specimens [36, 41, 43, 55]. In addition, cadavers do not recreate a realistic environment for ventriculoscopic work due to unnatural brain and ventricular compliance and consistency. Likewise, although laboratory animals are useful for surgical training, cost, ethical issues, and the lack of similarity with the human are problematic. The development of alternative realistic training methods is vital (Cover figure). The challenge is to provide not only realistic simulation of various pathologies but also standardized training milestones that allow a gradual progression in technical difficulty in concert with objective assessments of performance [61].

The use of 3-D renderings and virtual reality settings is still in the development phase and are quite costly for widespread use $[11,19]$. Examples in neurosurgery include simulators for ventriculostomy [27, 30,38], spine needle biopsy [28], pedicle screw placement $[26,31]$, diagnostic cerebral angiography [53], and aneurysm clipping. However, there may be limitations in the ability to transfer these "virtual skills" to physical reality $[20,39]$. Further development and evaluation is needed in regard to touch, tactile, and force feedback (which vary among simulators) and the complex task of reproducing an appropriate tridimensional environment for visuospatial task training $[4,5,20,22]$.

Despite ongoing investment in virtual reality simulator development, synthetic physical simulators are still generally considered the most reliable, effective, and cost-efficient $[3,8$, $12,21,23,25]$. The employment of physical simulators, designed specifically for surgical training, has become a promising method for neurosurgery training that provides effective results at a reasonable cost $[1,34,57,59]$. Many permit multiple uses of repetitive practice in order to reach the desired level of performance. They also provide the opportunity to obtain CT and MRI imaging to incorporate imageguided navigation into the training program [6]. Moreover, there is the possibility of developing various surgical environments (tumor appearance, consistency, bleeding, cystic content) that require the practice of different tasks with more realism and unquestionable safety $[6,61]$. A very important feature is the potential for high-fidelity haptic feedback that is not thus far supported by computer models. In general, these synthetic surgical simulators are reported to be interesting and appealing for participants to use [50], can serve as surrogate patients, and have the potential to enhance the quality of education in surgical anatomy and the teaching of basic and advanced open or endoscopic technical skills [24, 61].

It is important to emphasize that there is significant level I evidence demonstrating that technical skills acquired on simulated models directly transfer into performance improvements in the operating room, reinforcing their value in surgical training programs $[29,37]$. The ideal simulator has to be realistic in multiple dimensions. Simulation physics, optical properties, haptic feedback, and suitability for the required surgical tasks must be tested to ensure the quality of surgical training $[29,33]$. It is also mandatory to validate the ability of the simulation exercise to teach the desired skill set or technique [24]. The identification and measurement of errors permit assessment of the effectiveness of training that is specifically intended to reduce their incidence. Additionally, to be considered a useful tool for training, a simulator should be further evaluated regarding its overall quality. Despite a variety of ways to do it, every simulator should meet three major criteria: validity, reliability, and feasibility $[16,6]$.

Chopra et al. and Filho FV et al. showed that synthetic physical simulators can improve surgical performance $[7,16]$. Satava has suggested that a standardized simulator curriculum should include metrics specific to the skill being taught, common errors for the skill set, a specific curriculum for training the surgical skill, a method to capture outcomes, and a validation methodology [24, 49]. It has been suggested that when adopting a new training paradigm such as a simulatorbased curriculum, it is important to utilize the same language and terminology in order to preserve the standards of assessment [24, 18].

The development of effective surgical simulators is a milestone in the evolution of surgical education. Realistic simulators provide a safe and non-threatening learning context that not only promotes the development of skills but also allows for objective risk-free testing of a trainee's abilities prior to entering the operating room. Beyond pure technical proficiency, the cognitive skills of anatomical recognition, decision-making, and contingency planning can also be developed. And, independent learners can practice without constant supervision [50]. Additionally, these same models can be used in the process of initial certification as well as recertification of existing practitioners similar to performance assessment standards in the airline industry $[24,46]$.

Although the science of simulation for surgery, and more specifically pediatric neurosurgery, is still under development, the potential is very promising. New skill sets, such as those required for efficient and safe use of flexible endoscopy for 
neurosurgeons already adept with rigid endoscopes, will be more safely and efficiently transferred without the costs, risks, and logistical difficulties of learning new techniques in living patients.

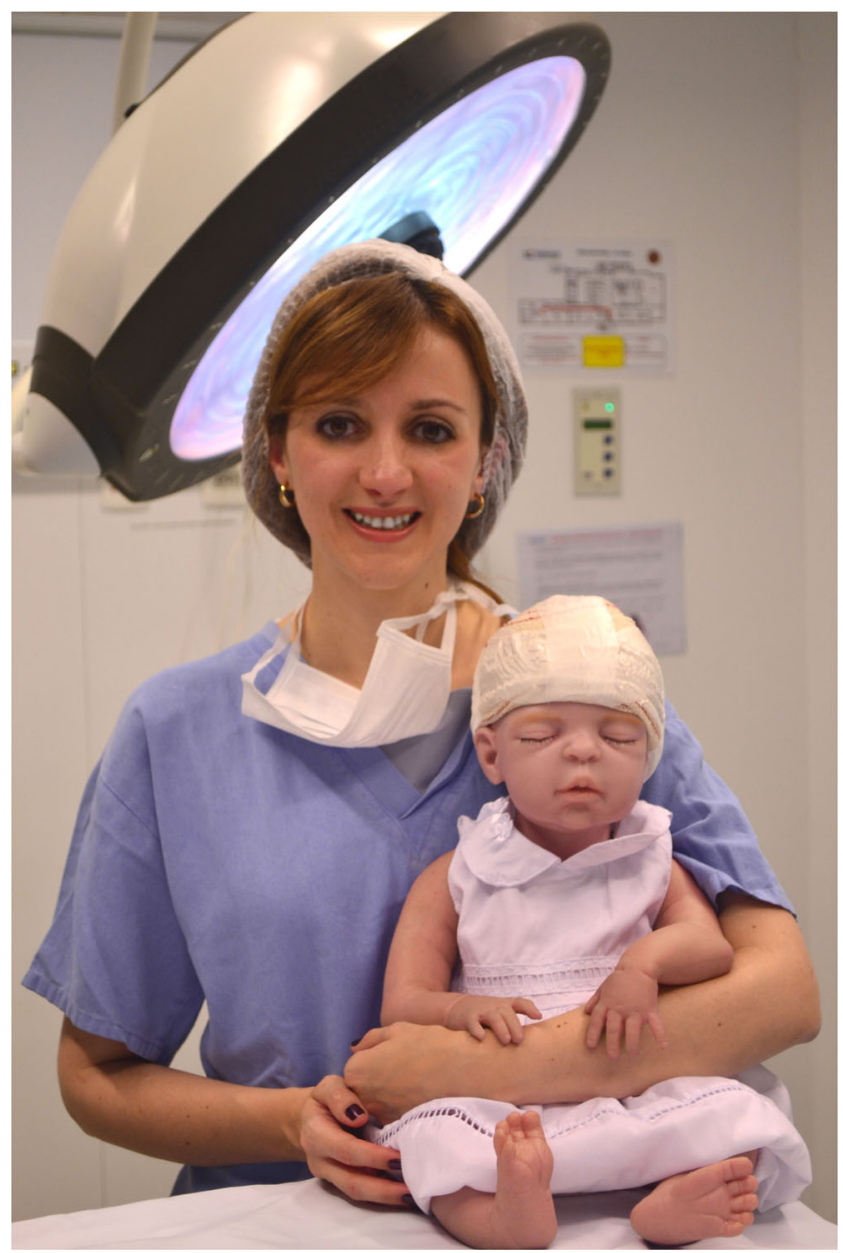

Cover figure: Dr Giselle Coelho and her realistic model, a mimic of an infant with craniosynostosis

\section{References}

1. Bakhos D, Velut S, Robier A, Al Zahrani M, Lescanne E (2010) Three-dimensional modeling of the temporal bone for surgical training. Otol Neurotol 31:328-334

2. Barnes RW, Lang NP, Whiteside MF (1989) Halstedian technique revisited. Innovations in teaching surgical skills. Ann Surg 210:118 121

3. Botden SM, Buzink SN, Schijven MP, Jakimowicz JJ (2007) Augmented versus virtual reality laparoscopic simulation: what is the difference? A comparison of the ProMIS augmented reality laparoscopic simulator versus LapSim virtual reality laparoscopic simulator. World J Surg 31:764-772

4. Burdea GC (1996) Force and touch feedback for virtual reality. Wiley, New York, NY
5. Burt DE (1995) Virtual reality in anaesthesia. Br J Anaesth 75:472-480

6. Coelho G, Kondageski C, Vaz-Guimaraes Filho F, Ramina R, Hunhevicz SC, Daga F, Lyra MR, Cavalheiro S, Zymberg ST (2011) Frameless image-guided neuroendoscopy training in real simulators. Minim Invasive Neurosurg 54:115-118

7. Chopra V, Gesink BJ, de Jong J, Bovill JG, Spierdijk J, Brand R (1994) Does training on an anaesthesia simulator lead to improvement in performance? Br J Anaesth 73:293-297

8. Condino S, Carbone M, Ferrari V, Faggioni L, Peri A, Ferrari M et al (2011) How to build patient-specific synthetic abdominal anatomies. An innovative approach from physical toward hybrid surgical simulators. Int J Med Robot 7:202-213

9. Committee on Quality of Health Care in America, Kohn LT, Corrigan JM, Donaldson MS (1999) To err is human: building a safer heath system. National Academy Press, Washington, DC

10. Cohen AR, Lohani S, Manjila S, Natsupakpong S, Brown N, Cavusoglu MC (2013) Virtual reality simulation: basic concepts and use in endoscopic neurosurgery training. Childs Nerv Syst 29(8):1235-44. doi:10.1007/s00381-013-2139-z

11. De Paolis LT, De Mauro A, Raczkowsky J, Aloisio G (2009) Virtual model of the human brain for neurosurgical simulation. Stud Health Technol Inform 150:811-815

12. Debes AJ, Aggarwal R, Balasundaram I, Jacobsen MB (2012) Construction of an evidence-based, graduated training curriculum for D-box, a webcam-based laparoscopic basic skills trainer box. Am J Surg 203:768-775

13. Dunnington G, Reisner L, Witzke D, Fulginiti J (1990) Structured single-observer methods of evaluation for the assessment of ward performance on the surgical clerkship. Am J Surg 159:423-426

14. Dutta S, Krummel TM (2006) Simulation: a new frontier in surgical education. Adv Surg 40:249-263

15. Ferenchick G, Simpson D, Blackman J, DaRosa D, Dunnington G (1997) Strategies for efficient and effective teaching in the ambulatory care setting. Acad Med 72:277-280

16. Filho FV, Coelho G, Cavalheiro S, Lyra M, Zymberg ST (2011) Quality assessment of a new surgical simulator for neuroendoscopic training. Neurosurg Focus 30:E17

17. Franzese CB, Stringer SP (2007) The evolution of surgical training: perspectives on educational models from the past to the future. Otolaryngol Clin North Am 40:1227-1235, vii

18. Fried GM (2006) Evaluation and validation of simulators. Presented at: SAGES/SLS Hands-on Course; April 27; Dallas, TX

19. Gallagher AG, Cates CU (2004) Virtual reality training for the operating room and cardiac catheterisation laboratory. Lancet 364 : $1538-1540$

20. Gorman PJ, Meier AH, Krummel TM (1999) Simulation and virtual reality in surgical education: real or unreal? Arch Surg 134:12031208

21. Halic T, Kockara S, Bayrak C, Rowe R (2010) Mixed reality simulation of rasping procedure in artificial cervical disc replacement (ACDR) surgery. BMC Bioinformatics 11(Suppl 6):S11

22. Hoffman H, Vu D (1997) Virtual reality: teaching tool of the twentyfirst century? Acad Med 72:1076-1081

23. Jain M, Tantia O, Khanna S, Sen B, Sasmal PK (2009) Hernia endotrainer: results of training on self-designed hernia trainer box. J Laparoendosc Adv Surg Tech A 19:535-540

24. Kavic MS (2006) Simulators: a new use for an old paradigm. JSLS 10(3):281-3

25. Khine M, Leung E, Morran C, Muthukumarasamy G (2011) Homemade laparoscopic simulators for surgical trainees. Clin Teach 8:118-121

26. Klein S, Whyne CM, Rush R, Ginsberg HJ (2009) CT-based patientspecific simulation software for pedicle screw insertion. J Spinal Disord Tech 22:502-506

27. Larsen OV, Haase J, Østergaard LR, Hansen KV, Nielsen H (2001) The Virtual Brain Project - development of a neurosurgical simulator. Stud Health Technol Inform 81:256-262 
28. Lathan C, Cleary K, Greco R (1998) Development and evaluation of a spine biopsy simulator. Stud Health Technol Inform 50:375-376

29. Lehmann KS, Ritz JP, Maass H, Cakmak HK, Kuehnapfel UG, Germer CT et al (2005) A prospective randomized study to test the transfer of basic psychomotor skills from virtual reality to physical reality in a comparable training setting. Ann Surg 241:442-449

30. Lemole GM Jr, Banerjee PP, Luciano C, Neckrysh S, Charbel FT (2007) Virtual reality in neurosurgical education: part-task ventriculostomy simulation with dynamic visual and haptic feedback. Neurosurgery 61:142-149

31. Luciano CJ, Banerjee PP, Bellotte B, Oh GM, Lemole M Jr, Charbel FT et al (2011) Learning retention of thoracic pedicle screw placement using a high-resolution augmented reality simulator with haptic feedback. Neurosurgery 69 (1 Suppl Operative):ons14-ons19

32. Ludmerer KM (1999) Time to heal. Oxford University Press, New York, NY, pp 320-321

33. Mattei TA, Frank C, Bailey J, Lesle E, Macuk A, Lesniak M, Patel A, Morris MJ, Nair K, Lin JJ (2013) Design of a synthetic simulator for pediatric lumbar spine pathologies. J Neurosurg Pediatr 12(2):192-201

34. McDougall EM, Kolla SB, Santos RT, Gan JM, Box GN, Louie MK, Gamboa AJ, Kaplan AG, Moskowitz RM, Andrade LA, Skarecky DW, Osann KE, Clayman RV (2009) Preliminary study of virtual reality and model simulation for learning laparoscopic suturing skills. J Urol 182:1018-1025

35. McGregor DB, Arcomano TR, Bjerke HS, Little AG (1995) Problem orientation is a new approach to surgical education. Am J Surg 170: 656-658

36. McLachlan JC, Bligh J, Bradley P, Searle J (2004) Teaching anatomy without cadavers. Med Educ 38:418-424

37. Palter VN, Grantcharov T, Harvey A, Macrae HM (2011) Ex vivo technical skills training transfers to the operating room and enhances cognitive learning: a randomized controlled trial. Ann Surg 253:886-889

38. Phillips NI, John NW (2000) Web-based surgical simulation for ventricular catheterization. Neurosurgery 46:933-937

39. Prystowsky JB, Regehr G, Rogers DA, Loan JP, Hiemenz LL, Smith KM (1999) A virtual reality module for intravenous catheter placement. Am J Surg 177:171-175

40. Pugh CM, Watson A, Bell RH Jr, Brasel KJ, Jackson GP, Weber SM, Kao LS (2009) Surgical education in the internet era. J Surg Res 156: $177-182$

41. Resch KDM, Perneczky A (1992) Use of plastined crania in neuroendoscopy. J Int Soc Plastination 6:15-16

42. Reznick RK (1993) Teaching and testing technical skills. Am J Surg 165:358-361

43. Rhoton AL Jr (2003) Operative techniques and instrumentation for neurosurgery. Neurosurgery 53:907-934

44. Richardson JD (2006) Training of general surgical residents: what model is appropriate? Am J Surg 191:296-300
45. Sachdeva AK, Loiacono LA, Amiel GE, Blair PG, Friedman M, Roslyn JJ (1995) Variability in the clinical skills of residents entering training programs in surgery. Surgery 118:300-308

46. Satava R (1996) Advanced simulation technologies for surgical education. Bull Am Coll Surg 81(7):77

47. Satava RM (2007) The future of surgical simulation and surgical robotics. Bull Am Coll Surg 92(3):13-9

48. Satava R (2002) Unmanned Air Vehicles (UAV) for vertical take-off and landing, such as helicopters and ducted-fan air vehicles. Courtesy Satava, Richard, and public sources

49. Satava R (2006) Where we've come, where we're going - curriculum, criteria, and the paradigm shift in surgical education. Presented at: SAGES/SLS Hands-on Course; April 27, Dallas, TX

50. Seymour NE, Gallagher AG, Roman S, O'Brien MK, Bansal VK, Andersen DK, Satava RM (2002) Virtual reality training improves operating room performance: results of a randomized, double-blinded study. Ann Surg 236(4):458-63, discussion 463-4

51. Sloan DA, Donnelly MB, Johnson SB, Schwartz RW, Strodel WE (1993) Use of an Objective Structured Clinical Examination (OSCE) to measure improvement in clinical competence during the surgical internship. Surgery 114:343-350

52. Sloan DA, Donnelly MB, Schwartz RW, Strodel WE (1995) The objective structured clinical examination. The new gold standard for evaluating postgraduate clinical performance. Ann Surg 222:735-742

53. Spiotta AM, Rasmussen PA, Masaryk TJ, Benzel EC, Schlenk R (2012) Simulated diagnostic cerebral angiography in neurosurgical training: a pilot program. J Neurointerv Surg

54. Thomas WEG (2008) The making of a surgeon. Surgery 26:400-402

55. Tubbs RS, Loukas M, Shoja MM, Wellons JC, Cohen-Gadol AA (2009) Feasibility of ventricular expansion postmortem: a novel laboratory model for neurosurgical training that simulates intraventricular endoscopic surgery. J Neurosurg 111:1165-1167

56. Walt AJ (1994) The uniqueness of American surgical education and its preservation. Bull Am Coll Surg 79:8-20

57. Weber D, Moser N, Rosslein R (1997) A synthetic model for microsurgical training: a surgical contribution to reduce the number of animal experiments. Eur J Pediatr Surg 7:204-206

58. Winckel CP, Reznick RK, Cohen R, Taylor B (1994) Reliability and construct validity of a structured technical skills assessment form. Am J Surg 167:423-427

59. Woodman PJ, Nager CW (2006) From the simple to the sublime: incorporating surgical models into your surgical curriculum. Obstet Gynecol Clin North Am 33:267-281, viii

60. Zymberg ST, Cavalheiro S (1996) Neuroendoscopia. A propósito de 30 casos. Revista de Neurociências 4:57-62

61. Zymberg ST, Vaz-Guimaraes Filho F, Lyra M (2010) Neuroendoscopic training: presentation of a new real simulator. Minim Invasive Neurosurg 53:44-46 